Int. J. Electrochem. Sci., 14 (2019) 6488 - 6499

\title{
Two-Step Approach Based on Solution Mixing and Hot Compaction for CNT/HDPE Nanocomposite Preparation
}

\author{
Ali Jaffal ${ }^{1}$, Rund Abu-Zurayk ${ }^{2,3}$, Mahmoud Al-Hussein ${ }^{1,2, *}$ \\ ${ }^{1}$ Department of Physics, The University of Jordan, Amman 11942, Jordan \\ ${ }^{2}$ Nanotechnology Center, The University of Jordan, Amman 11942, Jordan \\ ${ }^{3}$ Hamdi Mango Center for Scientific Research (HMCSR), The University of Jordan, Amman 11942, \\ Jordan \\ "E-mail: $\underline{\text { m.alhussein@ju.edu.jo }}$
}

doi: $1020964 / 2019.07 .59$

Received: 12 February 2019 / Accepted: 8 April 2019 / Published: 10 June 2019

We present a simple two-step approach for preparing large uniform sheets of multi wall carbon nanotube/high density polyethylene (MWCNT/HDPE) nanocomposites. Fragmented pieces of the nanocompoite produced by solution mixing are fused into large uniform sheets using hot compaction for short time. Nanocomposite samples with CNT content of 1,2, and $3 \mathrm{wt} \%$ were prepared using this approach and characterized using SEM, XRD and impedance spectroscopy. SEM images of the prepared nanocomposites illustrate homogenous dispersion of the CNTs between the PE crystalline lamellae. Crystallinity of the HDPE matrix increases with increasing the CNTs content due to their nucleating effect as revealed from the analysis of the XRD results. Impedance spectroscopy is used to determine the electrical conductivity of the nanocomposites. Nyquist plots and equivalent circuit modeling are used to extract the bulk resistance, which is in turn used to calculate the conductivity using self-developed fitting routines. Samples with only $1 \mathrm{wt} \%$ CNT content exhibit a conductivity of $2.3 \times 10^{-8} \mathrm{~S} / \mathrm{m}$ which increases more than 3 orders of magnitude with increasing the CNTs content due to the good dispersion and more interconnected conductive network within the HDPE matrix.

Keywords: Carbon nanotubes, High density polyethylene, Nanocomposites, Morphology, Electrical conductivity.

\section{$\underline{\text { FULL TEXT }}$}

(C) 2019 The Authors. Published by ESG (www.electrochemsci.org). This article is an open access article distributed under the terms and conditions of the Creative Commons Attribution license (http://creativecommons.org/licenses/by/4.0/). 